\title{
IMPACT OF GEOMETRY AND TRAFFIC CHARACTERISTICS ON SATURATION FLOW RATES AT SIGNALIZED INTERSECTIONS
}

\author{
Shimaa M. Helmy, Ibrahim H. Hashim \& Islam M. El-Desoky
}

\begin{abstract}
:
Signalized intersections play a critical role in the motion of both urban and arterial streets. One of the basic parameters for the design and analysis of signal controlled intersections is saturation flow rate. This paper reports the estimation of saturation flow rate (SFR) considering the prevailing conditions in Egypt, at signalized intersections. Accordingly, three main objectives are stated for this study: The first one is to investigate the effect of the geometric and traffic characteristics on saturation flow rates. The second objective is to estimate a calibration factor for using US-HCM2010 model to be suitable for the prevailing conditions in Egypt. The third objective is to develop a regression model for SFR considering intersection characteristics in Egypt.The required data for this study was collected at four signalized intersections in Shebin-Elkom city and in Tanta city using video recording technique. Geometric data and signal data were collected manually in the field. Data analysis showed that with the increase of the lane width, the saturation flow rate increases. The same conclusion can be extended to the turn-radius and vice versa with HV\%. While comparing the saturation flow calculated from US-HCM-2010 with measured saturation flows, it is observed that the values aren't matching with the difference in values as $7.6 \%$. After calibration, it can be seen that calibrated saturation flow based on US-HCM-2010 model is closer to the measured saturation flow with difference of $2.1 \%$. Many regression models were developed for saturation flow rate considering intersection characteristics in Egypt. The best model has $\mathrm{R}^{2}$ equals $78 \%$. This models includes 3 independent variables; $\% \mathrm{HV}$, lane width and lane type. The results indicated that, SFR measured using this model is closer to the field measured with a maximum difference of $1.2 \%$. The model is valid for estimating the saturation flow rate at signalized intersections in Delta region of Egypt that have similar characteristics.
\end{abstract}

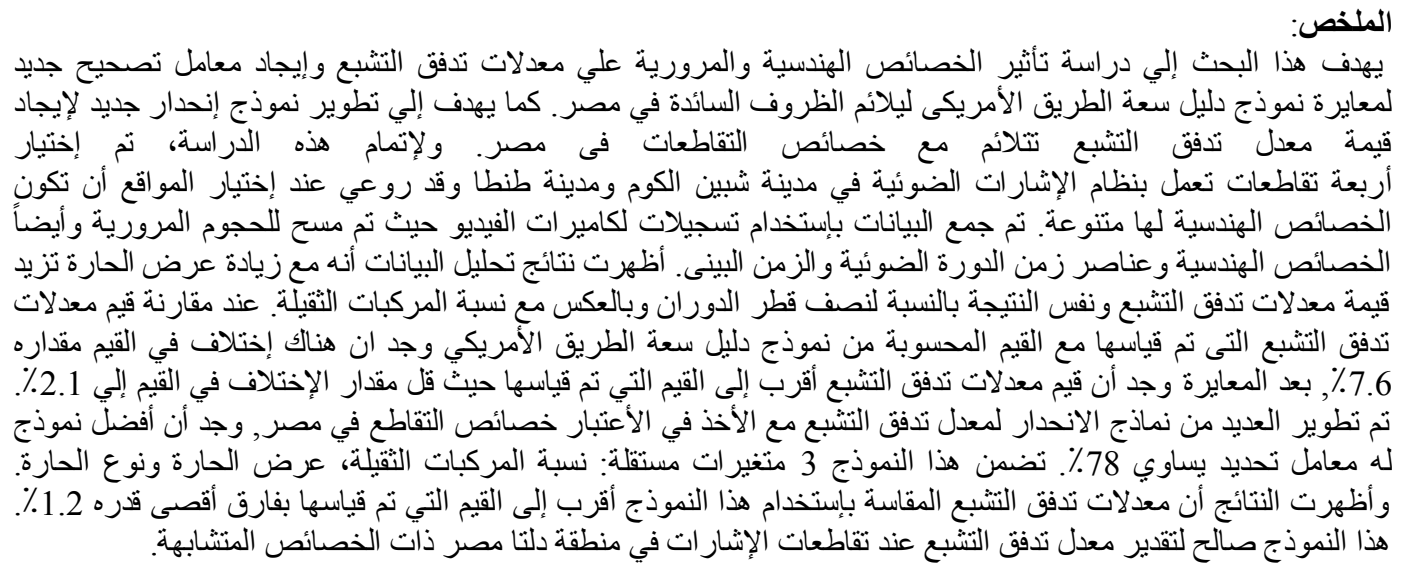

\section{INTRODUCTION}

Road intersections play an important role in the road network. They are the most complex locations in a traffic system and they have a very considerable influence on vehicle safety and movement's efficiency in the road network. A major characteristic of the urban road network is that it contains many intersections. Thus, traffic delay is often a prominent feature of urban road intersections [1].

Traffic characteristics and operations at the signalized intersections of developing cities are significantly different from those at the similar intersections of cities in developed countries [2]. Saturation flow rate is a fundamental parameter to measure the intersection capacity and time the traffic signals. Errors in saturation flow rates used to estimate vehicle delays carry over onto delay predictions and level of service LOS predictions. Therefore, it is necessary to study and to improve accuracy of the estimation of saturation flow rate. Due to the fact that driver behavior is the main determinate of saturation flow rate, a good 
understanding of the discharge headway of individual vehicles is essential in estimation of saturation headway and saturation flow rate [3].

Based on studying the previous researches, most likely it seems that no studies suggested saturation flow rate under the prevailing conditions in Egypt and the value suggested by HCM is not suitable. So, the research objective include:-

1) Estimation of the theoretical saturation flow rate using US-HCM 2010, and compare it with the measured values, then calibrate and validate the HCM model to use at signalized intersections in Egypt.

2) Development of a regression model for SFR considering intersection characteristics in Egypt.

\section{DEFINITION OF SATURATION FLOW RATE}

HCM-2010 [4] defines saturation flow rate as the flow in vehicles per hour that can be accommodated by the lane group assuming that the green phase were displayed $100 \%$ of the time. Under base geometric and operational conditions, the HCM-2010 estimates a lane's saturation flow rate to be 1900 passenger car per hour of green time per lane.

It was necessary to determine time headways, which is the elapsed time between the crossings of the rear axis of two successive vehicles over the stop line. The method takes into account a start-up delay which is caused by acceleration process after the signal has turned to green. This delay concerns only the first vehicles in the queue. Then a more or less constant saturation headway (or saturation flow rate) should be measured. Figure 1 shows the headways of vehicles as a function of their position in the queue at the intersection [5].

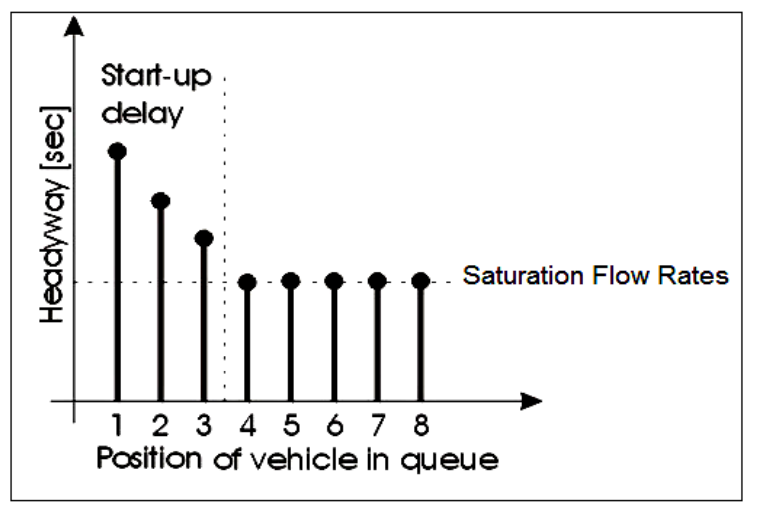

Figure (1) Concept of Saturation Flow Rate and Start-Up Delay [5]
In HCM 2010 [5] a saturation flow rate for each lane group is computed according to the following equation:

$$
S=S_{0} N f_{w} f_{h v} f_{g} f_{p} f_{b b} f_{a} f_{l u} f_{l t} f_{r t} f_{l p b} f_{r p b}
$$

where:

S : saturation flow rate $(\mathrm{veh} / \mathrm{h} / \mathrm{ln})$;

$\mathrm{S}_{0} \quad$ : ideal saturation flow rate usually taken as 1900 (pc/h/ln);

$\mathrm{N} \quad: \quad$ number of lanes in lane group;

$\mathrm{f}_{\mathrm{w}} \quad: \quad$ adjustment factor for lane width;

$\mathrm{f}_{\mathrm{hv}} \quad$ : adjustment factor for heavy vehicles in the traffic stream;

$\mathrm{f}_{\mathrm{g}} \quad: \quad$ adjustment factor for approach grade;

$\mathrm{f}_{\mathrm{p}} \quad: \quad$ adjustment factor for the existence of parking lane;

$\mathrm{f}_{\mathrm{a}} \quad$ : adjustment factor for area type (for $\mathrm{CBD}=0.90$; for all other areas $=1.00$ );

$\mathrm{f}_{\mathrm{bb}} \quad$ : adjustment factor for the blocking effect of local buses stopping within the intersection area;

$\mathrm{f}_{\mathrm{lu}} \quad: \quad$ adjustment factor for lane utilization;

$\mathrm{f}_{\mathrm{rt}}$ : adjustment factor for right turns in the lane group;

$\mathrm{f}_{\mathrm{lt}} \quad$ : adjustment factor for left turns in the lane group;

$\mathrm{f}_{\mathrm{lpb}} \quad$ : pedestrian adjustment factor for left-turn movements; and

\section{PREVIOUS STUDIES}

The Geometric condition is a term used to describe the roadway characteristics of the approach. They include the number of lanes, width of lanes, grades, and the allocation of the lanes for different uses, including the designation of a parking lane. Many researchers proved that geometric condition significantly affect the road networks; Dunlap [6] studied the suitability of default value imposed by HCM of saturation flow rate in southwestern Pennsylvania under the prevailing saturation flow rate to estimate ideal saturation flow. In this study, to investigate the HCM correction factor for lane width, the ideal saturation flow rate data were grouped into three categories: lane widths less than 12 feet, equal to 12 feet, and greater than 12 feet (values ranged from 10 feet to 14 feet). Initial findings showed that there was a statistically significant difference in the three categories. It is the same result founded by Arasan and Vedagiri [7] in India as it was found that; there is a significant increase in the saturation flow rate with an increase in the width of the approach road, as shown in Figure 2. 


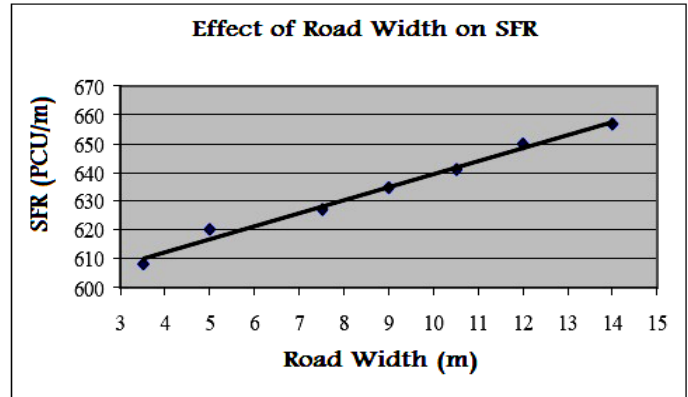

Figure (2) Effect of Road Width on Saturation Flow Rate [7]

Anusha et al. [8] studied saturation flow rate in Bangalore, India at a few signalized intersection. All signals specified are operative as pre-timed signals. It used the model proposed in US-HCM2000 to determine saturation flow rate. It concludes that saturation flow rate doesn't depend only on width of lanes, so experimental formula $(525 \mathrm{w})$ suggested for Indian conditions is unsuitable for determining the saturation flow.

Saturation flow rates of heterogeneous lanes (rightlane, left-lane, through-lane, through right-lane and through left-lane) at good weather conditions. Data collection by using video cameras in 36 intersections in Beijing at the evening peak period during heavy traffic and people familiar with the road [9]. It concludes that the results are reasonable. It was found that saturation flow rates are $1380 \mathrm{pc} / \mathrm{h} / \mathrm{Ln}$ of the right-turn lane, $1520 \mathrm{pc} / \mathrm{h} / \mathrm{Ln}$ of the left-turn lane, $1535 \mathrm{pc} / \mathrm{h} / \mathrm{Ln}$ of the through lane, $1457 \mathrm{pc} / \mathrm{h} / \mathrm{Ln}$ of the through-right lane and $1411 \mathrm{pc} / \mathrm{h} / \mathrm{Ln}$ of the through-left lane as shown in Figure 3.

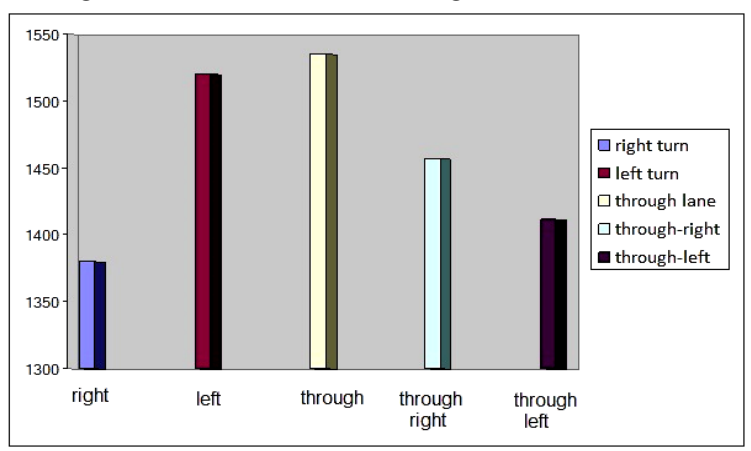

Figure (3) Results of Saturation Flow Rate [9]

Recently two studies have been implemented to study the impact of shared right-turn lanes and shared leftturn lane on SFR. In the first study, it was found that the estimated SFR produced by the developed model are close to the field-observed values, and extremely more accurate than the results obtained from the HCM procedures [10]. In the second study, results showed that efficient utilization of shared lane by through traffic can significantly improve SFR. At lower or higher pedestrian-bicycle volumes, SFRs are relatively reliable. While at middle levels of pedestrian demands, more random arrivals and interactions between pedestrians and vehicles lead to rather unstable SFR fluctuation [11].

Another study was conducted in Beijing [12], to quantitatively analyze the interaction of lane width and heavy vehicles on saturation flow rate and validate if there is an interaction between lane width and heavy vehicles. The result of the study showed that the lane width and heavy vehicles have an interaction. Then, an interaction based model was developed to estimate the mutual influence. The study provides integrative adjustment factor between the lane width and heavy vehicles mix rates. In addition, comparison between the integrative adjustment factor and the HCM adjustment factor is also conducted. It was found that the saturation flow rate is also influenced by interaction between factors. If the capacity was computed by multiplying the adjustment factors directly, the interaction between factors would be ignored. Therefore, the integrative adjustment factor is more suitable in the reduction of the saturation flow rate [12].

Rahman et al [13] studied the comparison between the saturation flow rates at signalized intersections in Yokohama, Japan and Dhaka, the capital of Bangladesh with HCM values. These results showed that the values of headway vary significantly between Yokohama and Dhaka. In case of Dhaka, the vehicles in the queue were more closely spaced than those in Yokohama which produces smaller headway values, as shown in Figure 4.

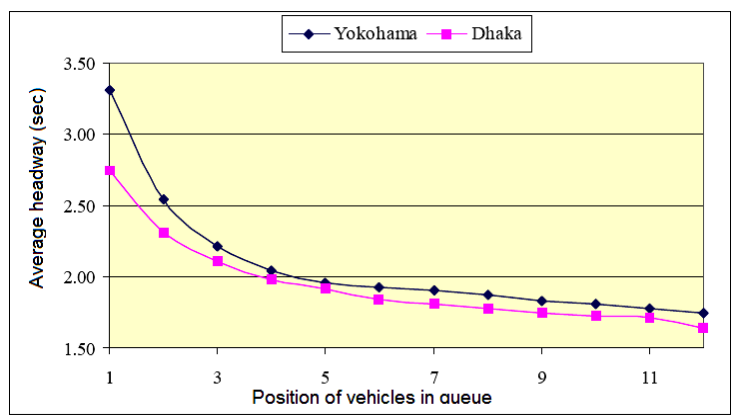

Figure (4) Comparison of Headway Values in Dhaka and Yokohama [13]

\section{DATA COLLECTION}

\subsection{Geometry}

The required data for this study was collected at four signalized intersections located in Shebin-Elkom City and Tanta City. The sites selected in Shebin-Elkom City are El-Gamsy intersection, Sabry Abo-Alam intersection, Atef El-Sadat intersection. In Tanta City El-Mohafza intersection was selected in this study. Geometric data are shown in Figures 5, 6, 7 and 8. The solid line indicates the studied movement direction and the dashed line indicates the movement direction which hasn't been studied. 


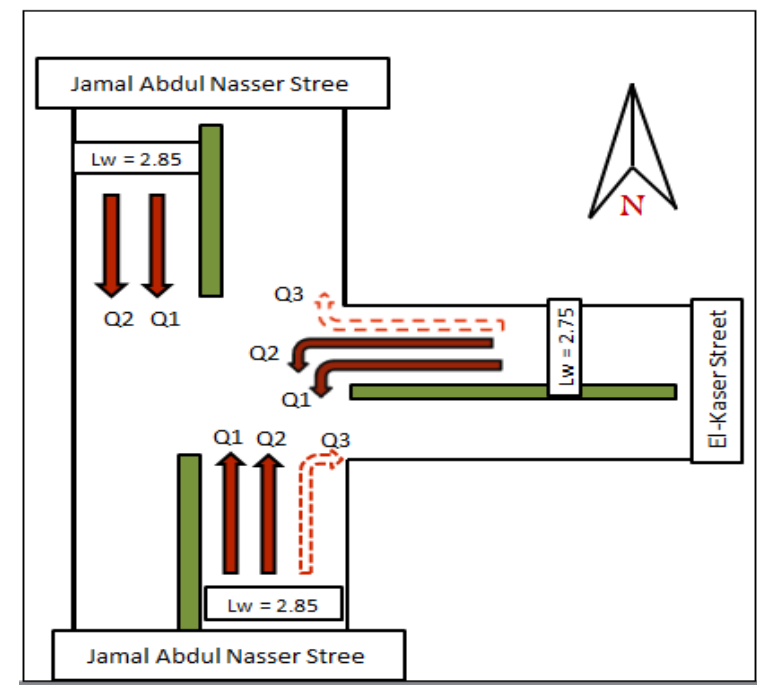

Figure (5) Geometric Data at El-Gamsy Intersection

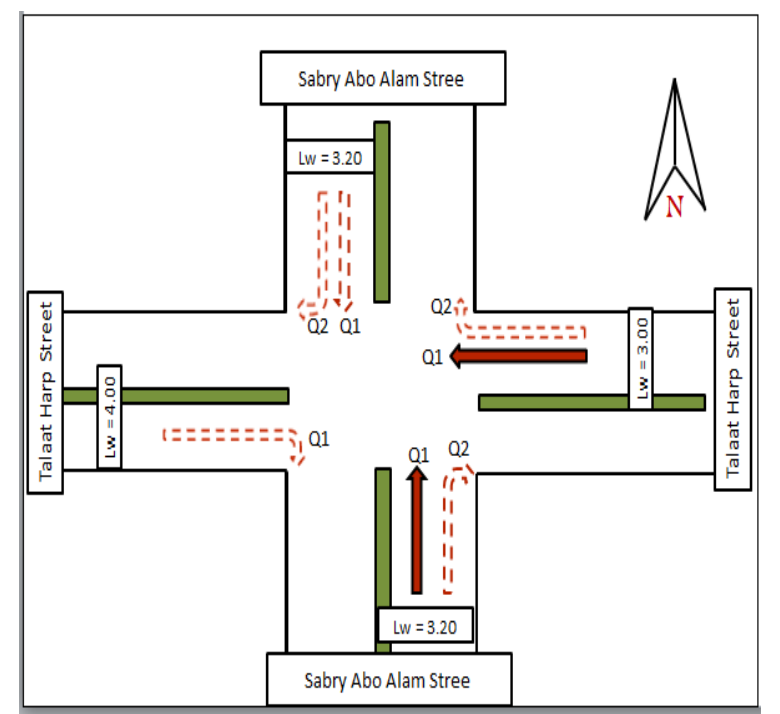

Figure (6) Geometric Data at Sabry Abo-Alam Intersection

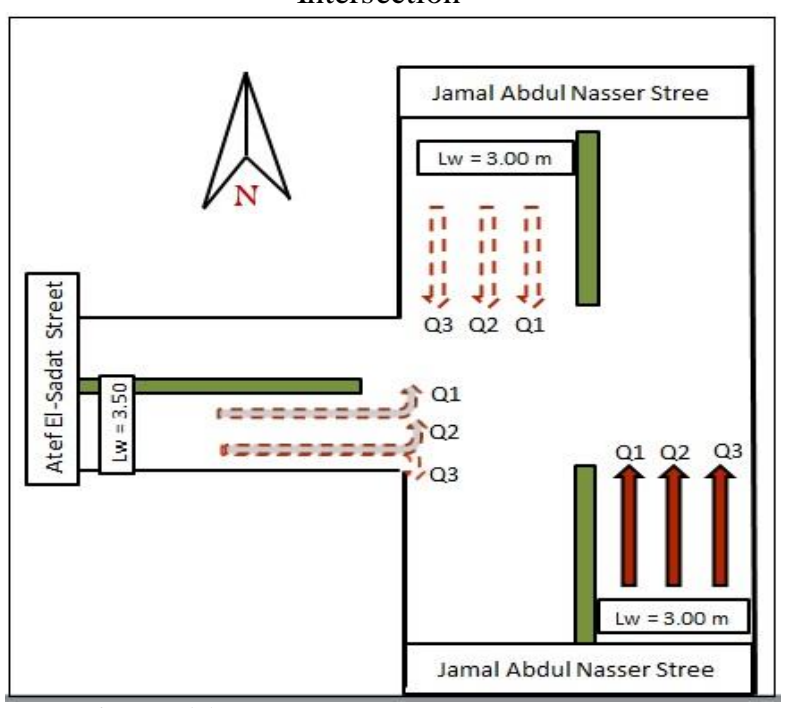

Figure (7) Geometric Data at Atef El-Sadat Intersection

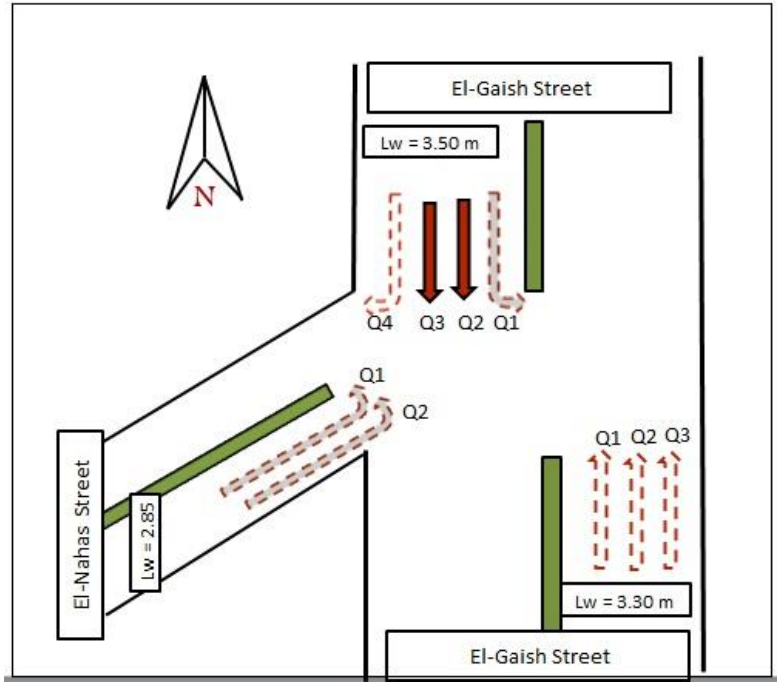

Figure (8) Geometric Data at El-Mohafza Intersections

\subsection{Traffic and Signal Phasing Data}

Traffic volumes for the intersection must be specified for each movement on each approach. Data collection was carried out in working days during the daylight hours. During data collecting periods, the weather was good and the pavement was dry. Table 1 shows the traffic volume intersections under the study.

Table (1): Characteristic of the Traffic Data

\begin{tabular}{|c|c|c|c|}
\hline \multirow{4}{*}{ Intersection } & Direction & $\begin{array}{c}\text { Lane } \\
\text { Movement }\end{array}$ & $\begin{array}{c}\text { Traffic } \\
\text { Volume } \\
\text { (veh/h) }\end{array}$ \\
\hline \multirow{4}{*}{$\begin{array}{c}\text { Sabry Abo- } \\
\text { Alam }\end{array}$} & North & $\mathrm{Q}_{1} \& \mathrm{Q}_{2}$ & 854 \\
\cline { 2 - 4 } & South & $\mathrm{Q}_{1} \& \mathrm{Q}_{2} \& \mathrm{Q}_{3}$ & 1409 \\
\cline { 2 - 4 } & East & $\mathrm{Q}_{1} \& \mathrm{Q}_{2} \& \mathrm{Q}_{3}$ & 763 \\
\cline { 2 - 4 } & North & $\mathrm{Q}_{1} \& \mathrm{Q}_{2}$ & 606 \\
\cline { 2 - 4 } & Eouth & $\mathrm{Q}_{1} \& \mathrm{Q}_{2}$ & 1032 \\
\hline \multirow{4}{*}{$\begin{array}{c}\text { Atef El- } \\
\text { Sadat }\end{array}$} & West & $\mathrm{Q}_{1} \& \mathrm{Q}_{2}$ & 899 \\
\cline { 2 - 4 } & North & $\mathrm{Q}_{1} \& \mathrm{Q}_{2} \& \mathrm{Q}_{3}$ & 473 \\
\cline { 2 - 4 } & South & $\mathrm{Q}_{1} \& \mathrm{Q}_{2} \& \mathrm{Q}_{3}$ & 1612 \\
\hline \multirow{3}{*}{\begin{tabular}{c} 
El-Mohafza \\
\cline { 2 - 4 }
\end{tabular}} & West & $\mathrm{Q}_{1} \& \mathrm{Q}_{2} \& \mathrm{Q}_{3}$ & 933 \\
\cline { 2 - 4 } & North & $\mathrm{Q}_{1} \& \mathrm{Q}_{2} \& \mathrm{Q}_{3}$ & 2758 \\
\cline { 2 - 4 }$\& \mathrm{Q}_{4}$ & $\mathrm{Q}_{1} \& \mathrm{Q}_{2} \& \mathrm{Q}_{3}$ & 1703 \\
\cline { 2 - 4 } & Weuth & $\mathrm{Q}_{1} \& \mathrm{Q}_{2}$ & 989 \\
\hline
\end{tabular}

The traffic signal was operating in a fixed-timed mode with a total cycle length of $86 \mathrm{~s}, 87 \mathrm{~s}, 79 \mathrm{~s}$ and $96 \mathrm{~s}$ for El-Gamsy intersection, Sabry Abo-Alam intersection, Atef El-Sadat intersection and ElMohafza intersection, respectively. 


\section{METHODOLOGY}

\subsection{Determination of Saturation Flow Rate (SFR)}

The methodology used in this research is determining saturation headway and saturation flow rates of each observed vehicle queue at each intersection. This was done by recording the time from the start of green time to the time each vehicle's rear wheels crossed the stop line using a video camera recording. HCM2010 [4] recommended a minimum of 15 cycles to be recorded for each approach to achieve a representative sample. In this study, 18 cycles were the minimum of cycle sampled taken, and there was a minimum of 8 vehicles required in the standing queue to collect the data to further ensure the validity of the sample.

In this study, field measurements were conducted on the through movement and left-turn movement at signalized intersections under study. Measurements are taken cycle by cycle. To reduce the data for each cycle, the time recorded for the fourth vehicle is subtracted from the time recorded for the last vehicle in the queue. This value represents the sum of the headways for the fifth through nth vehicle, where $n$ is the number of the last vehicle surveyed (which may not be the last vehicle in the queue). This sum is divided by the number of headways after the fourth vehicle [i.e., divided by $(n-4)$ ] to obtain the average headway per vehicle [4].

$\mathrm{H}_{\mathrm{s}}=$ (Time of the last vehicle surveyed - Time of the fourth vehicle) / ( $\mathrm{n}-4)$

After finding the value of saturation headway, the saturation flow rate was concluded by the simple equation:

$\mathrm{S}=3600 / \mathrm{Hs}$

where: $\mathrm{S}=$ saturation flow rate (veh / h / ln); and $\mathrm{H}_{\mathrm{s}}$ $=$ saturation headway $(\mathrm{sec})$.

\subsection{Measurement of Start-up Lost Time and Capacity}

Startup delay is an important factor because it affects the saturation flow rate and the capacity of roadway lanes at downstream traffic signals. Lost time is the time, in seconds, during which an intersection is not used effectively by any movement. Start-up lost time is the time lost due to driver reactions and vehicle acceleration, it is clear that start-up lost time depends on: driver reactions; type of vehicle; and vehicle acceleration [14]. The start-up lost time is estimated by the summation of the difference between the observed headway of each vehicle and the saturated headway as shown in Figure 9.
Start-up lost time $=\Sigma$ (Observed headway Saturated headway).......

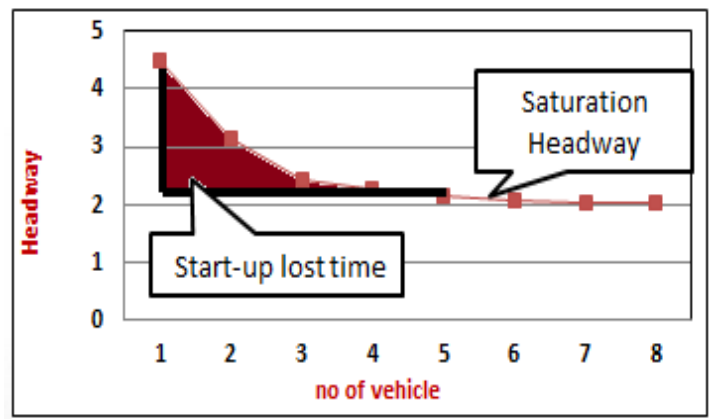

Figure (9) Saturated Headway and Start-up Lost Time

Capacity of signalized intersections is the key parameter in operating and performing traffic in urban roadways network. Increasing the capacity of intersections is the key factor for improving performance and quality of service of traffic movements over the whole urban roads network. Three approaches can be treated in order to increase the capacity of signalized intersection; optimizing traffic signal timing and phasing, maximizing saturation flow rate during the green period, and minimizing total delay time [15]. HCM-2010 defined capacity as the number of vehicles per hour of green time that can pass through the intersection. In a fullyutilized intersection, time is lost because of start-up time (the headway for the first 4 or 5 cars is larger than h) and slowdown [4]. The capacity is computed by this equation:

$\mathrm{C}_{\mathrm{i}}=\left(\mathrm{S}_{\mathrm{i}} * \mathrm{~g}_{\mathrm{i}}\right) / \mathrm{C}$

where: $\mathrm{C}_{\mathrm{i}}$ : capacity of lane group $\left.\mathrm{i}(\mathrm{veh} / \mathrm{h} / \mathrm{ln})\right) ; \mathrm{S}_{\mathrm{i}}$ : saturation flow rate for lane group $\mathrm{i}(\mathrm{veh} / \mathrm{h} / \mathrm{ln})$; $\mathrm{g}_{\mathrm{i}}$ : average effective green time $(\mathrm{sec})$; and $\mathrm{C}$ : average cycle time (sec).

Table 2 shows the capacity at each approach in study intersections.

Table (2): Capacity at Each Approach in the Studied Intersections

\begin{tabular}{|c|c|c|c|}
\hline Intersection & \multirow{2}{*}{ Direction } & Movement & $\begin{array}{c}\text { Capacity } \\
\text { (veh/h/ln) }\end{array}$ \\
\hline \multirow{4}{*}{ El-Gamsy } & \multirow{2}{*}{ North } & $\mathrm{Q} 1$ & 795 \\
\cline { 3 - 4 } & \multirow{2}{*}{ South } & $\mathrm{Q} 2$ & 792 \\
\cline { 3 - 4 } & & $\mathrm{Q} 1$ & 772 \\
\cline { 3 - 4 } & \multirow{2}{*}{ East } & $\mathrm{Q} 1$ & 768 \\
\cline { 3 - 4 } & & $\mathrm{Q} 2$ & 732 \\
\hline \multirow{3}{*}{$\begin{array}{c}\text { Sabry Abo- } \\
\text { Alam }\end{array}$} & South & $\mathrm{Q} 1$ & 796 \\
\cline { 3 - 4 } $\begin{array}{c}\text { Atef El- } \\
\text { Sadat }\end{array}$ & East & $\mathrm{Q} 2$ & 782 \\
\hline \multirow{2}{*}{\begin{tabular}{c} 
El-Mohafza \\
\cline { 3 - 4 }
\end{tabular}} & \multirow{2}{*}{ Nouth } & $\mathrm{Q} 1$ & 920 \\
\cline { 3 - 4 } & & $\mathrm{Q} 2$ & 918 \\
\cline { 3 - 4 } & & $\mathrm{Q} 3$ & 914 \\
\cline { 3 - 4 } & & $\mathrm{Q} 2$ & 868 \\
\hline
\end{tabular}




\subsection{Study the Effect of Lane Width, Turn Radius, Lane Type and \%HV on SFR}

Among the geometric conditions, the width of the lane has an effect on the capacity of the signalized intersections. To achieve the target of this study, data were grouped into three categories: lane widths less than $3.00 \mathrm{~m}$, equal to $3.00 \mathrm{~m}$, and more than $3.00 \mathrm{~m}$ (values ranged from $2.75 \mathrm{~m}$ to $3.5 \mathrm{~m}$ ) at the four intersection studies.

It can be deduced that, with the increase of lane width, the saturation headway decreases and saturation flow rate increases. Although there is a difference in some results because of the other different factors such as lane type, turn radius, traffic characteristics and drivers' behavior as shown in Figure 10.

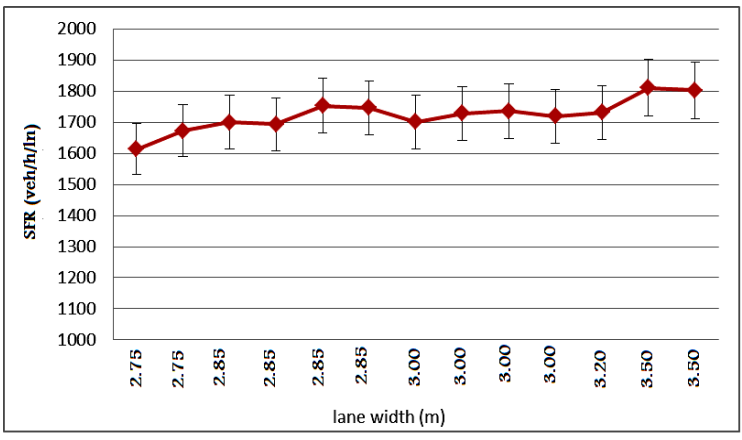

Figure (10) The Effect of Lane Width on Saturation Flow Rate.

When the lane width is $2.75 \mathrm{~m}$ and the turn radius is $30 \mathrm{~m}$, the saturation flow rate is $1671 \mathrm{veh} / \mathrm{h} / \mathrm{ln}$. In the other case when the lane width is $2.75 \mathrm{~m}$ and the turn radius is $25 \mathrm{~m}$, the saturation flow rate decreases to $1613 \mathrm{veh} / \mathrm{h} / \mathrm{ln}$. It can be deduced that, with the increase of the turn radius, the saturation flow rate increases slightly because the different in the turn radius is small.

When study the effect of lane type on SFR, it can be found that the saturation flow rate in through lane movement is greater than the value of saturation flow rate at the left turn movement. The maximum value of SFR for TH movement is $1810 \mathrm{veh} / \mathrm{h} / \mathrm{ln}$ at ElMohafza intersection and the minimum SFR for LT movement is $1613 \mathrm{veh} / \mathrm{h} / \mathrm{ln}$ at El-Gamsy intersection.

Percentage of $\mathrm{HV}$ is founded by dividing the number of $\mathrm{HV}$ into all number of vehicles passes the stop line. The sites were grouped into three groups; less than $4 \%, 4 \%$ to $10 \%$, and more than $10 \%$ (values ranged from $0.0 \%$ to $12.9 \%$ ). It can be found that, at most, the saturation flow rate decreases with the increase of $\mathrm{HV} \%$. There is a difference in some results because of the other different factors such as lane width, turn radius lane type and drivers' behavior.

\section{COMPARISION BETWEEN MEASURED SFR AND HCM-2010 ESTIMATED SFR}

While comparing the saturation flow calculated from US-HCM-2010 with measured saturation flows, it is observed that the values aren't matching with the difference in values as $7.6 \%$, because of the difference in roadway conditions, transportation conditions, the drivers' behavior and cultures et al. The value of $7.6 \%$ is lower difference but it can be improve it by getting calibrated model. Many regression models were developed for calibrated model. The best model has $\mathrm{R}^{2}=86 \%$ respectively as follows:

$\mathrm{F}_{\text {new }}=0.05+0.34 \mathrm{~L}_{\mathrm{w}}-0.2 \% \mathrm{HV}+0.6$

$\left(\% \mathrm{HV} / \mathrm{L}_{\mathrm{w}}\right)$

where: $F_{\text {new }}=$ the new calibrated factor to multiply it by the equation in HCM-2010; HV = the percentage of heavy vehicles; and $\mathrm{L}_{\mathrm{w}}=$ lane width $(\mathrm{m})$.

According to this model, the calibrated factor ranged from (1.03 to 1.2$)$, it is usually greater than 1.00 because the saturation flow calculated from USHCM-2010 is lower than the measured saturation flow rate. It can be seen that saturation flow calculated using calibrated US-HCM-2010 model is closer to the field measured saturation flow as shown in Table 3 and Figure 11. The difference now was decreased to about $2.1 \%$.

Table (3): Validation Results

\begin{tabular}{|c|c|c|c|c|c|}
\hline \multirow{2}{*}{$\begin{array}{l}\text { Inter- } \\
\text { section }\end{array}$} & \multirow[b]{2}{*}{$\begin{array}{l}\text { Dire- } \\
\text { ction }\end{array}$} & \multirow{2}{*}{$\begin{array}{c}\text { Move- } \\
\text { ment }\end{array}$} & \multicolumn{3}{|c|}{ Saturation Flow Rate (veh/h/ln) } \\
\hline & & & $\begin{array}{c}\text { HCM- } \\
2010\end{array}$ & Measured & Calibrate \\
\hline \multirow{6}{*}{$\begin{array}{c}\text { El- } \\
\text { Gamsy }\end{array}$} & \multirow{2}{*}{$\mathrm{N}$} & Q1 & 1587.6 & 1752.7 & 1784.9 \\
\hline & & $\mathrm{Q} 2$ & 1587.6 & 1746.2 & 1734.7 \\
\hline & \multirow{2}{*}{$\mathrm{S}$} & Q1 & 1545.7 & 1700.2 & 1623.9 \\
\hline & & Q2 & 1553.0 & 1693.2 & 1680.6 \\
\hline & \multirow{2}{*}{$\mathrm{E}$} & Q1 & 1381.3 & 1613.5 & 1661.9 \\
\hline & & Q2 & 1407.5 & 1671.7 & 1642.3 \\
\hline \multirow{2}{*}{$\begin{array}{l}\text { Sabry } \\
\text { Abo- } \\
\text { Alam }\end{array}$} & $\mathrm{S}$ & Q1 & 1644.2 & 1810.5 & 1803.9 \\
\hline & $\mathrm{E}$ & Q1 & 1627.0 & 1802.1 & 1785.0 \\
\hline \multirow{3}{*}{$\begin{array}{l}\text { Atef El- } \\
\text { Sadat }\end{array}$} & \multirow{3}{*}{$\mathrm{S}$} & Q1 & 1663.4 & 1730.8 & 1779.8 \\
\hline & & Q2 & 1673.1 & 1700.3 & 1715.8 \\
\hline & & Q3 & 1681.4 & 1728.1 & 1799.1 \\
\hline \multirow{2}{*}{$\begin{array}{c}\text { El- } \\
\text { Mohafza }\end{array}$} & \multirow{2}{*}{$\mathrm{N}$} & Q2 & 1665.0 & 1725.1 & 1781.5 \\
\hline & & Q3 & 1663.4 & 1718.7 & 1779.8 \\
\hline
\end{tabular}


Shimaa M. Helmy, Ibrahim H. Hashim \& Islam M. El-Desoky, "Impact of Geometry and Traffic Characteristics...."

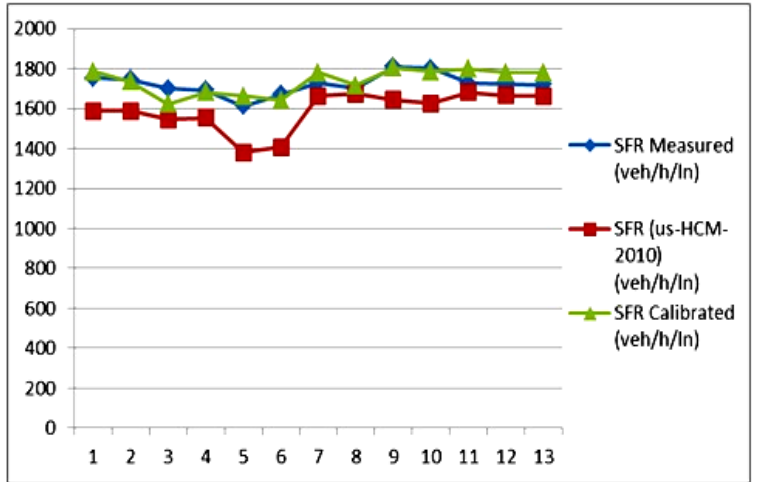

Figure (11) Comparison of SFR Calibrated and Measured SFR.

\section{DEVELOPMENT OF A REGRESSION MODEL FOR SFR IN EGYPT}

To develop a regression model for saturation flow rate considering intersection characteristics in Egypt, many models were trialed and then the best one was chosen. It was found that these models were selected on the basis of coefficient of determination $\left(\mathrm{R}^{2}\right)$. They are significant at the $95 \%$ confidence level as the significance of $\mathrm{F}$ statistic $<0.001$. The chosen model has $\mathrm{R}^{2}=78 \%$ and Sig. $\mathrm{F}$ change $<0.005$. This model is as follows:

$\mathrm{SFR}=1497-0.28 \% \mathrm{HV}+18.8 \mathrm{~L}_{\mathrm{w}}{ }^{2}+61.4 \mathrm{~L}_{\text {type }} \ldots .(6)$

where:- SFR : saturation flow rate (veh/h/ln); $\mathrm{L}_{\mathrm{w}} \quad$ : Lane width (m); \%HV: percentage of heavy vehicles; and $\mathrm{L}_{\text {type }}$ : Lane type $=1.00$ For $\mathrm{TH}$ movement and $=0$ For LT movement.

According to this model, the signs of the coefficients are in the expected direction. $\mathrm{L}_{\mathrm{w}}{ }^{2}$ showed positive sign; this means that saturation flow rate tends to increase as lane width increase. \% HV showed negative singe; this means that saturation flow rate tends to decrease as \% $\mathrm{HV}$ increase. Lane type showed positive sign; this means that saturation flow rate tends to increase as lane type is TH movement and tends to decrease as lane type is LT. Table 4 and Figure 12 show the results of saturation flow rate using the regression model.

It can be seen that saturation flow measured using a regression model is closer to the field measured saturation flow. Percentage of difference after using the regression model is $1.2 \%$.

It could be drawn that the regression model proposed in this study is valid for estimating the saturation flow rate at signalized intersections in Egypt that have similar characteristics.
Table (4): Results of Saturation Flow Rate using a Regression Model

\begin{tabular}{|c|c|c|c|c|}
\hline \multirow{2}{*}{ Intersection } & \multirow{2}{*}{$\begin{array}{l}\text { Dire- } \\
\text { ction }\end{array}$} & \multirow{2}{*}{$\begin{array}{c}\text { Move- } \\
\text { ment }\end{array}$} & \multicolumn{2}{|c|}{ Saturation Flow Rate $(\mathrm{veh} / \mathrm{h} / \mathrm{ln})$} \\
\hline & & & Measured & regression model \\
\hline \multirow{6}{*}{ El-Gamsy } & \multirow{2}{*}{$\mathrm{N}$} & Q1 & 1752.7 & 1708.3 \\
\hline & & $\mathrm{Q} 2$ & 1746.2 & 1709.1 \\
\hline & \multirow{2}{*}{$\mathrm{S}$} & Q1 & 1700.2 & 1710.2 \\
\hline & & $\mathrm{Q} 2$ & 1693.2 & 1709.4 \\
\hline & \multirow{2}{*}{$\mathrm{E}$} & Q1 & 1613.5 & 1635.8 \\
\hline & & $\mathrm{Q} 2$ & 1671.7 & 1636.3 \\
\hline \multirow{2}{*}{$\begin{array}{c}\text { Sabry Abo- } \\
\text { Alam }\end{array}$} & $\mathrm{S}$ & Q1 & 1810.5 & 1787.3 \\
\hline & $\mathrm{E}$ & Q1 & 1802.1 & 1787.3 \\
\hline \multirow{3}{*}{$\begin{array}{l}\text { Atef El- } \\
\text { Sadat }\end{array}$} & \multirow{3}{*}{$\mathrm{S}$} & Q1 & 1730.8 & 1723.6 \\
\hline & & $\mathrm{Q} 2$ & 1700.3 & 1748.3 \\
\hline & & Q3 & 1728.1 & 1727.0 \\
\hline \multirow{2}{*}{ El-Mohafza } & \multirow{2}{*}{$\mathrm{N}$} & Q2 & 1725.1 & 1726.2 \\
\hline & & Q3 & 1718.7 & 1726.7 \\
\hline
\end{tabular}

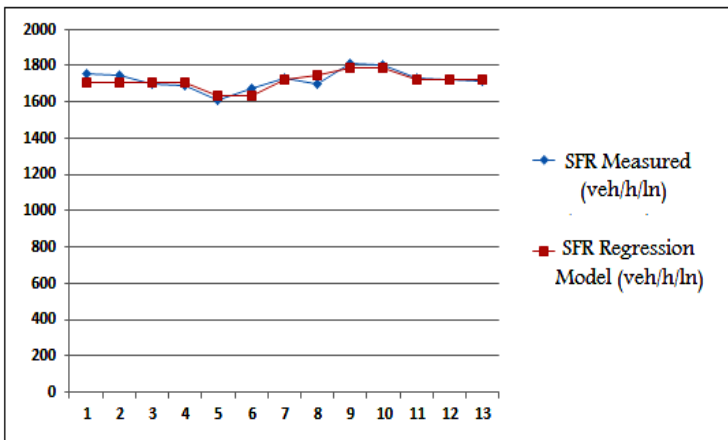

Figure (12) Comparison of Saturation Flow Rate Measured and Regression Model.

Base saturation flow rate was measured during ideal conditions (3.6-meter lane width; no heavy vehicles; flat gradient; no parking or bus stops near the intersection; uniform movement type, only straight movement and no pedestrians or cyclists). It was found that the base saturation flow rate for Egypt is $1788 \mathrm{pc} / \mathrm{h} / \mathrm{ln}$. It could be drawn that the base SFR in this study is valid for estimating the SFR at signalized intersections in Egypt that have similar characteristics. Figure 13 shows the comparison of the base saturation flow rates at different countries/cities including base saturation flow rate in Egypt.

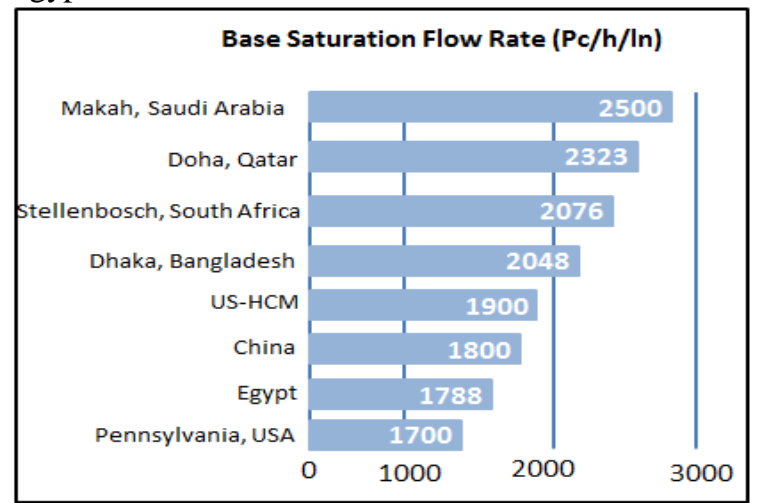

Figure (13) Comparison of the Base SFR at Different Cities and Base SFR Measured in Egypt. 


\section{CONCLUSIONS \& RECOMMENDATIONS}

This paper is mainly aimed at investigating the impact of geometric and traffic characteristics on saturation flow rates. The first objective of this study is to investigate the effect of the geometric and traffic characteristics on saturation flow rates. The second objective is to estimate a calibration factor for using US-HCM-2010 model to be suitable for the prevailing conditions in Egypt. The third objective is to develop a regression model for SFR considering intersection characteristics in Egypt.

- For the first objective, the results found that with the increase of the lane width, the saturation flow rate increases. The same conclusion can be extended to the turn-radius. Saturation flow rate in through lane movement is greater than the value of saturation flow rate at the left turn movement. It also can be found that with the increase of $\mathrm{HV} \%$ the saturation flow rate decreases.

- For the second objective, the results showed that saturation flow measured using calibrated USHCM-2010 model (by incorporating $F_{\text {new }}$ ) is closer to the field measured saturation flow. The difference after calibration is about $2.1 \%$.

- For the third objective, the best model for estimating SER in Egypt include \%HV, lane width and lane type. The result based on this model is closer to the field measured saturation flow with difference of $1.2 \%$.

- The regression model proposed in this study is valid for estimating the saturation flow rate at signalized intersections in Delta region of Egypt that have similar characteristics of the area under study, it is useful for practitioners to measure the intersection capacity and time the traffic signals. It was found that the base saturation flow rate for Egypt is $1788 \mathrm{pc} / \mathrm{h} / \mathrm{ln}$.

- It is recommended that further research should be conducted in other intersections in different Governorates in Egypt to generalize the findings of this study and be capable of estimating the saturation flow rate at any signalized intersection.

\section{REFERENCES}

[1] Mutcd, (2012). "Manual on Uniform Traffic Control Devices." Federal Highway Administration, Washington, D.C.

[2] Hossain, M., (2001). "Estimation of saturation flow at signalized intersections of developing cities: a micro-simulation modeling approach." Transport Research Part. A 35, pp. 123-141.
[3] Shao, C.Q., and Liu, X.M., (2012). "Estimation of Saturation Flow Rates at Signalized Intersections." Discrete Dynamics in Nature and Society, Article ID 720474, 9 pages.

[4] Transportation Research Board (TRB), (2010). "Highway Capacity Manual." 5th Edition, National Research Council, Washington, D.C.

[5] Asamer, J., Zuylen, H., (2011). "Saturation Flow under Adverse Weather Conditions." In Transportation Research, TRB 2011.

[6] Dunlap, B., (2005). "Field Measurement of Ideal Saturation Flow Rate from the Highway Capacity Manual."Morgantown, West Virginia.

[7] Arasan, V.T., Vedagiri, P., (2006). "Estimation of Saturation Flow of Heterogeneous Traffic Using Computer Simulation." Proceedings 20th European Conference on Modeling and Simulation Wolfgang Borutzky.

[8] Anusha, C.S., Verma, A., and Kavitha, G., (2012). "Effects of Two-Wheelers on Saturation Flow at Signalized Intersections in Developing Countries." Journal of Transportation Engineering, (ASCE).

[9] Shang, H., Zhang, Y., and Fan, L., (2014). "Heterogeneous Lanes Saturation Flow Rates at Signalized Intersections." The 9th International Conference on Traffic \& Transportation Studies (ICTTS), Vol.138, pp. 3-10.

[10] Chen, p., Qi, H., and Sun, J., (2014). "Investigation of Saturation Flow on Shared Right-turn Lane at Signalized Intersections." Submitted for the 93rd Annual Meeting of the Transportation Research Board, TRB 2014.

[11] Chen, P., Nakamure, H., and Asano, M., (2010). "Analysis of Saturation Flow Rate Fluctuation for Shared Left-Turn Lane at Signalized Intersection in Japan: A Case Study." In Transportation Research, TRB 2011.

[12] Wanchao, Z., and Kuan, Y.X., (2011). "Study on Mutual Interaction of Lane Width and Heavy Vehicles on Through Lane Saturation Flow Rate at Signalized Intersections." TRB 90th Annual Meeting in Washington, D.C.

[13] Rahman, M., Hassan, T., and Ahmed, S.N., (2005). "Comparison of Saturation Flow Rate at Signalized Intersections in Yokohama and Dhaka." Proceedings of the Eastern Asia Society for Transportation Studies, Vol. 5, pp. 959 - 966.

[14] Gonzalez, L.F.C., (2006). "Discharge Headway at Signalized Intersections in Monterrey Nuevo Leon, Mexico."

[15] Hashim, I., and Shawky, M., (2010). "A beforeand-after Study on Traffic Signal Countdown Control Device." Proceedings of the 8th ICCAE Conference. 